\title{
Evaluation of Psychological and Sexual Effects of Female Genital Mutilation (Circumcision)
}

\author{
Zakaria Mahran Obaid ${ }^{1}$, Ahmed Wahhed-Allah Amer ${ }^{1}$, Mohammed Abdel Fatah El \\ Mahdy $^{2}$, Amira Elmaadawy Barakat Mohammed ${ }^{1 *}$
}

\author{
Departments of ${ }^{1}$ Dermatology, Venereology \& Andrology and ${ }^{2}$ Psychiatry, Faculty of \\ Medicine, Al-Azhar University, Damietta, Egypt
}

*Corresponding author: Amira Elmaadawy Barakat Mohammed, E-Mail: dr_miro89@yahoo.com, Mobile: 01009601432

\begin{abstract} suicide. difference between the studied groups. lubrication".

\section{INTRODUCTION}

According to a 2013 UNICEF report covering 29 countries in Africa and the Middle East, Egypt has the highest total number of women that have undergone female genital mutilation (FGM) (27.2 million) in the region, while the highest percentage (prevalence) of FGM was in Somalia (98\%) $)^{(\mathbf{1})}$. FGM harms women's physical health throughout their lives (2). Circumcised women have reported several sexual problems including a reduction in all her sexual cycle as sexual desire, arousal, excitement, orgasm, and dyspareunia at varying levels ${ }^{(3)}$.
\end{abstract}

Background: female genital mutilation (FGM), also known as female circumcision (FC), but more recently as female genital mutilation/cutting (FGM/C) according to the World Health Organization (WHO), has occurred in many forms in all societies. The psychosocial consequences include post-traumatic stress disorder (PTSD), anxiety disorders, panic disorders, depression and suppression of feeling and thinking, and sometimes attempted

Objective: To evaluate sexual and psychological effects of female genital mutilation.

Patients and Methods: The two groups were compared as regard many demographic data such as age, level of education, associated chronic diseases and previous gynecological history. The results revealed no significant difference between the two groups in the educational level. The females in the two groups also showed significant difference in their agreement with the process and subsequently in their future decision in performing circumcision for their daughters. Other demographic data included in this study revealed no

Results: The study used different questionnaires and scores to compare the sexual satisfaction and psychological effects of the females in the study. For assessment of sexual satisfaction, Female Sexual Function Index (FSFI) questionnaire translated into Arabic was used and showed no significant difference between the two groups except for only a single domain"

Conclusion: Concerning the psychiatric analysis of the two groups, Anxiety Hamilton score and Depression Beck score were used and showed no statistically significant difference between the two groups in the two scores. Also 19\% of the females in the group of FGM showed positive symptoms for post-traumatic stress disorder (PTSD).

Keywords: Post-traumatic stress disorder, female genital mutilation, female circumcision

The psychosocial consequences of FGM include post-traumatic stress disorder (PTSD), anxiety disorders, panic disorders, depression and suppression of feeling and thinking, and sometimes attempted suicide ${ }^{(4)}$.

These effects are due to psychological trauma of the painful procedure, sense of humiliation and being cheated by parents, use of physical force by those performing the procedure, negative genital image, lack of sense of 
ownership of their bodies, destructive sexual life, and infertility ${ }^{(4,5)}$.

\section{AIM OF THE WORK}

The aim of the present work is to evaluate sexual and psychological effects of female genital mutilation.

\section{PATIENTS AND METHODS}

\section{Study population}

Between January 2018 and September 2018, a total of 200 women: 100 sexually active who were subjected to FGM/C while, 100 sexually active weren't subjected to FGM/C. All women were married and below the age of 50 and were collected from the outpatient clinics of Damietta Al-Azhar University Hospital, informed consent was obtained from the participants. The study was approved by the Ethics Board of Al-Azhar University.

\section{All patients were subjected to:}

\section{History taking:}

Demographic characteristics, including age, age of marriage, educational level (primary, prep, secondary school or university degree) were assessed in all women.

Our study also included data pertaining to the age at time of $\mathrm{FGM} / \mathrm{C}$, who performed the FGM/C (physicians or not), their agreement with FGM/C (agree/disagree) their decision about doing FGM/C for their daughter.

\section{Clinical examination:}

Clinical examination was done to exclude any systemic or debilitating disease, and exclude any psychological illness.

\section{Assessment of female sexual function} our study by:

Female sexuality was assessed in

Arabic translated version of FSFI questionnaire (6) which is a brief, multidimensional, validated tool for assessment of FSF during sexual activity, consists of a 19-item regarding sexual function domains consisted of: sexual desire, arousal, lubrication, orgasm, satisfaction and pain during sexual activity/intercourse.
For each of the 19 questions there were 5 possible answers with score (0-5) that was calculated and the significance of each of them in comparison to the control group is determined.

\section{Assessment of psychological function}

Anxiety was assessed by using Hamilton Anxiety Rating Scale HAM-A (7):

The HAM-A was developed to measure the severity of anxiety symptoms, the scale consists of 14 items that measure both psychic anxiety (mental agitation and psychological distress) and somatic anxiety (physical complaints related to anxiety).

each item is scored on a scale of 0 (not present) to 4 (severe), with a total score range of $0-56$, where $y$, where $<17$ indicates mild severity, 18-24 mild to moderate severity and 25-30 moderate to severe.

Depression was assessed by Beck's Depression Inventory ${ }^{(8)}$ for depression:

It is 21-item self-report multiplechoice developed to measure the intensity, severity, and depth of depression.

Items are rated on a 4-point scale ranging from 0 to 3 based on severity of each item. The maximum total score is 63 . Where 0:13 indicate minimum depression, 14:19 indicates mild depression, 20:28 indicates moderate depression and 29:63 indicates severe depression.

Post-Traumatic Stress Disorder was assessed by Davidson Trauma ScaleDSM-IV ${ }^{(9)}$ :

DSM is self-rating scale for assessing the frequency of post-traumatic stress disorder symptoms, It is consists of 17 items that are classified into 3 clusters. Which are Intrusive, Avoidance/Numbing, and Hyper arousal that can be scored separately?

Diagnosis of PTSD is made by: One item from Intrusion, three items from avoidance, one item from Hyperarousal Statistical analysis of the data

Data were fed to the computer and analyzed using IBM SPSS software 
package version 22.0. Qualitative data were described using number (frequency) and Percent.

Quantitative data were described using mean and standard deviation or median and range after testing normality using Kolmogorov-Smirnov test. Significance of the obtained results was judged at the 5\% level. All tests were 2tailed.
Categorical variables were compared using Chi square $\left(\square^{2}\right)$ test, and continuous variables were compared using independent sample t-test (with normally distributed data) or Mann-Whitney U test [expressed as Z] (if the data is not normally distributed).

$$
\text { All tests were considered }
$$

significant if $P$ value $<0.05$

\section{RESULTS}

Table (1): Analysis of circumcision in the females included in the study:

\begin{tabular}{|c|c|c|}
\hline \multicolumn{3}{|c|}{ Age of circumcision (in years) } \\
\hline Median (min-max) & \multicolumn{2}{|c|}{10 (at birth-18) } \\
\hline \multicolumn{3}{|c|}{ Who performed circumcision } \\
\hline & Number & Percentage \\
\hline Not medical staff & 42 & $21 \%$ \\
\hline Medical staff & 58 & $29 \%$ \\
\hline Total & 100 & $50 \%$ \\
\hline \multicolumn{3}{|c|}{ Satisfaction with circumcision } \\
\hline No & 144 & $72 \%$ \\
\hline Yes & 56 & $28 \%$ \\
\hline Total & 200 & $100 \%$ \\
\hline \multicolumn{3}{|c|}{ Doing circumcision for daughters } \\
\hline No & 136 & $68 \%$ \\
\hline Yes & 19 & $9.5 \%$ \\
\hline May be & 45 & $22.5 \%$ \\
\hline Total & 200 & $100 \%$ \\
\hline
\end{tabular}

Table (2): Comparison and analysis of different factors between the two groups included in the study:

\begin{tabular}{|c|c|c|c|c|c|c|}
\hline \multirow{2}{*}{} & \multicolumn{2}{|c|}{$\begin{array}{c}\text { Group } \\
\text { With FGM }\end{array}$} & \multicolumn{2}{c|}{$\begin{array}{c}\text { Group } \\
\text { Without FGM }\end{array}$} & \multirow{2}{*}{ P } \\
\cline { 2 - 5 } & Count & Percent & Count & Percent & & \\
\hline \multicolumn{8}{|c|}{ Education Level } \\
\hline Secondary & 8 & $4 \%$ & 6 & $3 \%$ & \multirow{2}{*}{1.021} & \multirow{2}{*}{0.784} \\
\hline University & 92 & $46 \%$ & 94 & $47 \%$ & \\
\hline Condom & 4 & $3.4 \%$ & 6 & $5.1 \%$ & & \\
\hline \multicolumn{7}{|c|}{ Agreement with circumcision } \\
\hline No & 55 & $27.5 \%$ & 89 & $44.5 \%$ & \multirow{2}{*}{28.671} & \multirow{2}{*}{$<0.0001^{*}$} \\
\hline Yes & 45 & $22.5 \%$ & 11 & $5.5 \%$ & & \\
\hline
\end{tabular}


Table (3): Comparison and analysis of the items of Female Sexual Function Index between the two groups included in the study

\begin{tabular}{|c|c|c|c|c|}
\hline & Group & Mean \pm SD & t-test & $\mathrm{P}$ \\
\hline \multirow{2}{*}{ Desire } & with FGM & $4.29 \pm 1.14$ & \multirow{2}{*}{0.261} & \multirow{2}{*}{0.794} \\
\hline & Without FGM & $4.25 \pm 1.24$ & & \\
\hline \multirow{2}{*}{ Arousal } & with FGM & $4.49 \pm 1.12$ & \multirow{2}{*}{0.255} & \multirow{2}{*}{0.799} \\
\hline & Without FGM & $4.53 \pm 1.11$ & & \\
\hline \multirow{2}{*}{ Lubrication } & with FGM & $4.68 \pm 0.98$ & \multirow{2}{*}{2.100} & \multirow{2}{*}{$0.037 *$} \\
\hline & Without FGM & $4.96 \pm 0.89$ & & \\
\hline \multirow{2}{*}{ Orgasm } & with FGM & $4.54 \pm 1.19$ & \multirow{2}{*}{1.278} & \multirow{2}{*}{0.203} \\
\hline & Without FGM & $4.75 \pm 1.09$ & & \\
\hline \multirow{2}{*}{ Satisfaction } & with FGM & $4.98 \pm 1.17$ & \multirow{2}{*}{0.386} & \multirow{2}{*}{0.700} \\
\hline & Without FGM & $5.04 \pm 1.18$ & & \\
\hline \multirow{2}{*}{ Pain } & with FGM & $4.58 \pm 1.05$ & \multirow{2}{*}{0.957} & \multirow{2}{*}{0.340} \\
\hline & Without FGM & $4.43 \pm 1.12$ & & \\
\hline \multirow{2}{*}{ Total score } & with FGM & $27.33 \pm 5.61$ & \multirow{2}{*}{0.852} & \multirow{2}{*}{0.395} \\
\hline & Without FGM & $27.95 \pm 4.88$ & & \\
\hline
\end{tabular}

* The star means ecstatically significance differances between the tow groups

Table (4): Comparison and analysis of the items of Anxiety Hamilton Score and Depression Beck Score between the two groups included in the study

\begin{tabular}{|c|c|c|c|c|}
\hline & Group & Mean Rank & Z score & $\mathrm{P}$ \\
\hline \multirow{2}{*}{$\begin{array}{l}\text { Anxiety Hamilton } \\
\text { score }\end{array}$} & with FGM & 103.63 & \multirow{2}{*}{0.886} & \multirow{2}{*}{0.376} \\
\hline & Without FGM & 96.41 & & \\
\hline \multirow{2}{*}{$\begin{array}{c}\text { Depression Beck } \\
\text { Score }\end{array}$} & with FGM & 101.5 & \multirow{2}{*}{0.366} & \multirow{2}{*}{0.715} \\
\hline & Without FGM & 98.52 & & \\
\hline
\end{tabular}

Table (5): Number and percentage of females with positive response at post traumatic stress disorders (PTSD) score in group I (with FGM).

\begin{tabular}{|c|c|c|}
\hline & Number & Percentage \\
\hline $\begin{array}{c}\text { Females with positive } \\
\text { response for PTSD in group I } \\
\text { (with FGM) }\end{array}$ & 19 & $19 \%$ \\
\hline
\end{tabular}

\section{DISCUSSION}

The World Health Organization (WHO) defines FGM as "all procedures that involve partial or total removal of the external female genitalia or other injury to the female genital organs for non-medical reasons" ${ }^{(10)}$.

Female sexual dysfunction is defined as a disorder of sexual desire, orgasm, arousal, and sexual pain that results in significant personal distress ${ }^{(11)}$. Sexual dysfunction after FGM is a very important issue ${ }^{(12)}$.
In our study, the mean age of the participants in the study was 22.5 years with nearly $75 \%$ of them are within the age of twenties. Also, in our study, the median age of circumcision was 10 years with minimum age at birth and maximum age for performing circumcision was 18 years. It has been known that FGM is typically performed on young girls between 4 and 12 years old; however, the procedure may be carried out shortly after birth right up until just before a girl is married ${ }^{(13)}$. 
Traditionally, FGM was done by non-medical stuff as midwives, but the practice is increasingly medicalized and more health-care providers are performing the procedure trying to decrease the incidence of complications (Mahmoud et al., 2014) (14). The results of our study supported this point of view where about $58 \%$ of the females with FGM were performed by physicians while $42 \%$ of them weren't.

This was also supported by the results reported by Ismail et al. ${ }^{(15)}$ as nearly half of FGM cases in their study $(49.7 \%)$ were performed by physicians. This also came in accordance with the results reported by El-nashar and Abdelhady ${ }^{(16)}$ and El-Zanaty \& Way ${ }^{(17) .}$

The results of our study showed no significant difference between the educational level of females within the two groups with a greater number of university level of education females who didn't undergo FGM ( $p=0.784)$.

This was also coming in accordance with the results of Mahmoud (18) who revealed that $39.3 \%$ of cases included in their study got university education and more versus $43.3 \%$ of their control group.

This also came in contrast to the results of many studies that revealed higher significant difference in the educational level between the females who and who didn't undergo FGM. Anderson et al. ${ }^{(19)}$, Raheem et al. ${ }^{(20)}$, Ismail et al. ${ }^{(15)}$ and many other authors reported the negative association between the educational level and the act of FGM.

Establishing a relationship between a woman's FGM status and her educational level can often be misleading, as FGM usually takes place before education is completed. It is more important to comment on the educational level of the parents or the care providers of the daughters. Unfortunately, there was no available data about the educational level of the parents in this study. This point has been demonstrated by Raheem et al. (20) who revealed a significant difference in the educational level of the parents between the cases and the controls.

There was a highly significant difference between the participants within the two groups in their agreement with the process of FGM/C ( $\mathrm{p}=<0.0001)$, This might be the cause that affected their decisions in performing $\mathrm{FGM} / \mathrm{C}$ to their daughters in the future that also revealed highly significant difference between the two groups $(p=0.003)$.

The results of our work came in opposite to those reported by Mahmoud (18) who showed that $52.6 \%$ of cases of females with FGM were convinced with this practice. Moreover, $46 \%$ actually redid it or plan to do it for their daughters. In addition to that, the study conducted in Switzerland on the African immigrants revealed that $75 \%$ of female who had FGM were satisfied with the process without further illustration of the aspects of these satisfaction ${ }^{(21) .}$

Also, in our study, there was no statistically significant difference in sexual quality of life scores between women who have undergone FGM and those who have not with the FGM women as illustrated by the total FSFI score. When the individual items of the FSFI were compared between the two groups, no significant difference were detected between them in desire, arousal, orgasm, satisfaction and pain during the sexual intercourse. The only item that showed significant difference between the two groups was the lubrication during the sexual act.

The absence of significant difference in this study could be due to the low number of females recruited within each group in the study. Most of studies recruited larger number. Another reason for absence of significant difference is shame among females and inability to express their opinions about sexual life freely.

In agreement with the results of our study, it has been revealed that there is no difference in the total FSFI score between the cases and control groups in the results of a study performed by 
Abdulcadir et al. ${ }^{(22)}$. They have assumed that it happened because a smaller clitoris could be associated with an improved perception of the genitals and gender identity in some women, resulting in better sexual function.

Moreover, Catania et al. (23) showed in their results that 57 women with type III FGM/C reported higher scores than controls in several FSFI domains, but this study was confounded by the unmatched control group consisting mainly of western women.

In the study of Alsibiani and Rouzi ${ }^{(24)}$ on 260 women in Saudi Arabia, no difference in the mean desire or pain score was observed. While, there were statistically significant differences in the arousal, lubrication, orgasm, and satisfaction, as well as the overall sexual function score between circumcised and control women.

On the contrary of the results of this current study, the results of a study conducted by Mahmoud (18) showed a significant association between FGM and female sexual function, where reduction of all individual FSFI domain scores (namely desire, arousal, lubrication, orgasm, satisfaction and pain). The total score of female sexual function for cases was significantly lower than their control (14.3 \pm 5.93 for cases versus $25.9 \pm 3.44$ for control) $(\mathrm{P}=0.000)$.

Biglu et al. ${ }^{(25)}$ also proved that the total scores for circumcised women was significantly lower than control women $(17.9 \pm 5.39$ versus $25.3 \pm 4.34$ respectively, $\mathrm{p}=0.001)$. Also, Anis et al. (26) found that women with FGM/C had significantly lower scores on all domains except pain.

A recent study conducted in Assiut University hospitals in Egypt in 2017 that had two groups of females with and without FGM; each group of 197 has also shown the highly significant difference in the sexual function between the both groups. The control group had higher score in all domains of FSFI and the total score as well than the cases ${ }^{(15) .}$
The psychological consequences of FGM may be explained by many factors, such as the lateness of the procedure (during adolescence or early adulthood) as a sort of punishment or a weakness on the part of the parents, or worry over the state of the genitals and future marital life, as well as fear of infertility (27)(28). FGM girls are often aware that their status is not generally accepted in society ${ }^{(29) .}$ Furthermore, in schools and other public forums, people are increasingly taught about the negative effects of FGM, creating a continuous pressure on FGM girls ${ }^{(30)}$.

In our study we used anxiety Hamilton score and Beck's depression analysis to assess the difference between the two groups in presence of anxiety and depression. However, the current results revealed no statistically significant difference between the females within the case and control group ( $\mathrm{P}$ value is 0.376 and 0.715). Also, about $19 \%$ of the participants within group 1 showed positive response in PTSD.

In contrast to our results, Ahmed et al. ${ }^{(13)}$ performed a study to assess the effects of FGM on the long term psychological consequences of the participant females. Psychological health data analysis revealed that FGM girls had significantly higher scores for somatisation $(33.5 \pm 3.7$ vs. $20.6 \pm 4.2)$, depression $(31.7 \pm 3.3$ vs. $26.3 \pm 4.9)$, anxiety ( $32.1 \pm 3.1$ vs. $21.2 \pm 3.8)$, phobic anxiety $(20.4 \pm 5.6$ vs. $14.6 \pm 1.4)$ and hostility $(19.6 \pm 5.4$ vs. $16.4 \pm 2.8)$ than those in the non-FGM group.

These results in previous study came in agreement with those of Kizilhan (29), who found a significantly higher prevalence of depression disorder (33.6\%), anxiety disorder (45.6\%) among Kurdish girls in northern Iraq who had undergone FGM compared with a non-FGM group.

Chibber et al. ${ }^{(31)}$ found that the most prevalent psychological disturbances among FGM girls were affective disorders, including anxiety and depression (58\%). In addition to that, 
Vloeberghs et al. ${ }^{(32)}$ found that $33 \%$ of FGM women from five different African countries met the criteria for affective or anxiety disorders and $16 \%$ had PTSD.

On the contrary, FGM/C provides a psychological relief to a child who is made to believe and celebrate the cultural act in the community where female genitals are seen as dirty or a source of enthralling temptation. The female child feels satisfied despite the pain, of being made clean and marriageable like every other female in the community rather than becoming despised and made the target of ridicule with no one in the community to marry her ${ }^{(33)}$.

An Egyptian study conducted in Benha University Hospital by Elnashar and Abdelhady ${ }^{(16)}$, assessing the impact of FGM on the health of newly married women, demonstrated that FGM women had significant mental problems regarding somatization, anxiety and phobic anxiety; however, FGM had no significant effect on depression and hostility. Their study population was generally older than our study population, which may explain the differences.

Another study performed in 2015 on the African immigrants in Netherlands revealed that about a sixth reporting scores above the threshold for PTSD and a third reporting severe levels of depression or anxiety from a total number of 66 with FGM included in the study (34). Those African immigrants can give a good indicator for PTSD associated with circumcision because they transferred to more developed countries where can express their sexual and psychological needs freely. This usually not happen here in Egypt because of the problems of daily life and the society tradition which make expression of sexual needs as a kind of welfare or even a kind of shame.

The strength points in this study include the use of a standardized questionnaire that has been validated for the Egyptian population, including equal numbers of females within the two groups and using multiple psychological scores to assess the psychological effects of FGM on the long run.

limitations in this work do exist including low number of participants in the study. Although other studies utilized less number, but large number may cause change in the outcomes of both physical and psychological outcomes. Also, difficulty to obtain information from many females because of traditions and shyness made the study to take more prolonged time.

\section{CONCLUSION}

FGM is more frequent in females in families who previously performed FGM to older females. number of females with FGM who agreed with the FGM is less than who didn't agree. However, this ratio is still higher than the group without FGM and this could explain the difference of the future decision for performing circumcision for their daughters between the two groups. As regards the sexual and psychological effects in this study the only difference was lubrication.

\section{REFERENCES}

1. De Schrijver L, Leye E and Merckx $M$ (2016): A multidisciplinary approach to clitoral reconstruction after female genital mutilation: the crucial role of counselling. The European Journal of Contraception \& Reproductive Health Care, 21 (4): 269-275.

2. Reisel D and Creighton SM (2015): Long term health consequences of Female Genital Mutilation (FGM): Maturitas, 80: 48-51.

3. Berg $R$ and Denison $E$ (2012): Does female genital mutilation/cutting (FGM/C) affect women's sexual functioning? A systematic review of the sexual consequences of FGM/C. 
Sexuality research and social policy, 9 (1): 41-56.

4. World Health Organization (2016): Health risks of female genital mutilation

(FGM).https://www.who.int/reproduc tivehealth/topics/fgm/health_consequ ences_fgm/en/

5. Rushwan $H$ (2013): Female genital mutilation: A tragedy for women's reproductive health. African Journal of Urology, 19 (3): 130-133.

6. Anis TH, Gheit SA, Saied HS and Al_kherbash SA (2011): Arabic translation of Female Sexual Function Index and validation in an Egyptian population. The journal of sexual medicine, 8(12): 3370-3378.

7. Hamilton MAX (1959): The assessment of anxiety states by rating. British journal of medical psychology, 32(1): 50-55.

8. Beck AT, Ward CH, Mendelson M, Mock J and Erbaugh J (1961): An inventory for measuring depression. Archives of general psychiatry, 4(6): 561-571.

9. Davidson JR, Book SW, Colket JT, Tupler LA, Roth $S$ et al. (1997): Assessment of a new self-rating scale for post-traumatic stress disorder. Psychological medicine, 27(1):153-160.

10.World Health Organization (2008): "Eliminating female genital mutilation: an interagency statement. https://www.who.int/reproductivehealt h/publications/fgm/9789241596442/en/

11. Raina $R$, Pahlajani $G$, Khan $S$, Gupta S, Agarwal A et al. (2007): Female sexual dysfunction: classification, pathophysiology, and management. Fertil Steril., 88:127384.

12. Watson MA (2005): Female circumcision from Africa to the Americas: slavery to the present. Soc Sci J., 42:421-37.

13. Ahmed MR, Shaaban MM, Meky HK, Arafa AME, Mohamed TY et al (2017): Psychological impact of female genital mutilation among adolescent Egyptian girls: a crosssectional study. The European Journal of Contraception \& Reproductive Health Care, 22(4): 280-285.

14. Andro A, Lesclingand $M$, Grieve $M$ and Reeve $P$ (2016): Female genital mutilation, Overview and current knowledge. Population, 71(2):217296.

15. Ismail $S$ A, Abbas A M, Habib D, Morsy $H$, Saleh $M A$ and Bahloul $M$ (2017): Effect of female genital mutilation/cutting; types I and II on sexual function: case-controlled study. Reproductive health, 14(1): 108.

16. Elnashar $A$ and Abdelhady $R$ (2007): The impact of female genital cutting on health of newly married women. International Journal of Gynecology \& Obstetrics, 97(3): 238244.

17. El-Zanaty $F$ and Way A (2014):

Egypt Demographic and Health Survey .Cairo: Ministry of Health. https://dhsprogram.com/pubs/pdf/f r220/fr220.pdf

18. Mahmoud MIH (2016): Effect of female genital mutilation on female sexual function, Alexandria, Egypt. Alexandria Journal of Medicine, 52(1):55-59.

19. Andersson SHA, Rymer J, Joyce $D W$, Momoh $C$ and Gayle CM (2012): Sexual quality of life in women who have undergone female genital mutilation: a case-control study. BJOG: An International Journal of Obstetrics \& Gynaecology, 119(13): 1606-1611.

20. Raheem TAA, El-tahalawi SM, Raia N MA, Elsary AY and Ibrahem, KM (2018): The effect of female genital mutilation on couple sexual function. International Journal of Community Medicine and Public Health, 5(3):905911.

21. Wuest S, Raio L, Wyssmueller D, Mueller MD, Stadlmayr W, Surbek DV and Kuhn A (2009): Effects of female genital mutilation on birth 
outcomes in Switzerland. BJOG: An International Journal of Obstetrics \& Gynaecology, 116(9): 1204-1209.

22. Abdulcadir J, Botsikas D, Bolmont $M$, Bilancioni A, Djema D A, Demicheli $F B$ and Petignat $P$ (2016): Sexual anatomy and function in women with and without genital mutilation: a cross-sectional study. The journal of sexual medicine, 13(2): 226-237.

23. Catania L, Abdulcadir O, Puppo V, Verde JB, Abdulcadir $J$ and Abdulcadir $D$ (2007): Pleasure and orgasm in women with female genital mutilation/cutting (FGM/C). The journal of sexual medicine, 4(6): 1666-1678.

24. Alsibiani SA and Rouzi AA (2010): Sexual function in women with female genital mutilation. Fertility and sterility, 93(3):722-724.

25. Biglu MH, Farnam A, Abotalebi P, Biglu $S$ and Ghavami $M$ (2016): Effect of female genital mutilation/cutting on sexual functions. Sexual \& Reproductive Healthcare, 10: 3-8.

26. Anis TH, Gheit SA, Awad HH and Saied HS (2012): Effects of female genital cutting on the sexual function of Egyptian women, a cross-sectional study. The journal of sexual medicine, 9(10): 2682-2692.

27. Kessler RC, Sonnega A, Bromet E, Hughes $M$ and Nelson $C B$ (1995): Posttraumatic stress disorder in the National Comorbidity Survey, Archives of general psychiatry, 52(12): 1048-1060.
28. Yasin YA (2014): Prevalence of female genital mutilation among school girls in El Mansoura Center, El-Dakahlia Governorate, Egypt. IOSR Journal of Dental and Medical Sciences, 13: 11-76.

29. Kizilhan JI (2011): Impact of psychological disorders after female genital mutilation among Kurdish girls in Northern Iraq. The European Journal of Psychiatry, 25(2):92-100.

30. Bartlett $A$ (2006). Female Genital Mutilation: Treating the Tears. Psychiatric Bulletin, 30(2):78-78.

31. Chibber R, El-Saleh E and El Harmi $J$ (2011): Female circumcision: obstetrical and psychological sequelae continues unabated in the 21st century. The Journal of Maternal-Fetal \& Neonatal Medicine, 24(6):833-836.

32. Vloeberghs E, Van der Kwaak A, Knipscheer $J$ and van den Muijsenbergh M (2012): Coping and chronic psychosocial consequences of female genital mutilation in the Netherlands. Ethnicity \& health, 17(6):677-695.

33. Odukogbe ATA, Afolabi BB, Bello OOand Adeyanju AS (2017): Female genital mutilation/cutting in Africa. Translational andrology and urology, 6(2): 1.

34. Knipscheer J, Vloeberghs E, van der Kwaak $A$ and van den Muijsenbergh $M$ (2015): Mental health problems associated with female genital mutilation. BJPsych bulletin, 39(6); 273-277. 